\title{
Office-based physical activity: mapping a social ecological model approach against COM-B
}

\author{
Yasmin F. van Kasteren ${ }^{1 *}$ (D) Lucy K. Lewis ${ }^{2}$ and Anthony Maeder ${ }^{1}$
}

\begin{abstract}
Background: There are growing concerns over the health impacts of occupational sedentary behaviour on officebased workers and increasing workplace recognition of the need to increase physical activity at work. Social ecological models provide a holistic framework for increasing opportunities for physical activity at work. In this paper we propose a social ecological model of office-based physical activity and map it against the Capability Motivation Opportunity (COM-B) framework to highlight the mechanisms of behaviour change that can increase levels of physical activity of office-based workers.

Discussion: The paper proposes a social ecological model of physical activity associated with office-based settings. The model considers opportunities for both incidental and discretionary activities, as well as macro and micro factors on both socio-cultural and physical dimensions. The COM-B framework for characterising behaviour change interventions is used to highlight the underlying mechanisms of behaviour change inherent in the model.

Summary: The broad framework provided by social ecological models is important for understanding physical activity in office-based settings because of the non-discretionary nature of sedentary behaviour of office-based work. It is important for interventions not to rely on individual motivation for behaviour change alone but to incorporate changes to the broader social ecological and physical context to build capability and create opportunities for more sustainable change.
\end{abstract}

Keywords: Physical activity, Sedentary behaviour, Office work, Social ecological model, COM-B

\section{Background}

There is a large body of evidence supporting the importance of physical activity for health and wellbeing. Sedentary behaviour is defined as "any waking behaviour characterized by an energy expenditure $\leq 1.5$ metabolic equivalents (METs), while in a sitting, reclining or lying posture" [1]. Sedentary behaviour has been linked to increased risk of cardiovascular disease, cancer, weight gain, obesity and musculoskeletal pain [2-5]. For office workers, the nature of their work increases exposure to sedentary behaviour inherent in desk bound and increasingly computer related work activities [6]. For office workers, as much as $77 \%$ of time at work is spent in sedentary behaviour, and this is often accumulated in

\footnotetext{
* Correspondence: yasmin.vankasteren@flinders.edu.au

${ }^{1}$ Flinders Digital Health Research Centre, Flinders University, GPO Box 2100,

Adelaide, South Australia 5001, Australia

Full list of author information is available at the end of the article
}

prolonged bouts $[7,8]$. Both employers and employees have a vested interest in building opportunities for physical activity into their workday and their work place activities. Workplace initiatives involving physical exercise, lifestyle and ergonomics can improve employee wellbeing, their ability to perform their work tasks and productivity through reduced sick leave [9].

Over the last 15 years there has been an increasing push by health authorities and workplace health and safety to reduce the health risks associated with sedentary behaviour at work by increasing physical activity of office workers and by breaking up prolonged bouts of sedentary behaviour [10-15].

Current guidelines recommend that adults should engage in at least $20 \mathrm{~min}$ a day (or $150 \mathrm{~min}$ a week) of moderate to vigorous physical activity (MVPA) preferably in bouts of $10 \mathrm{~min}$ or more [16-18]. Health guidelines also recommend reducing sedentary behaviour, in 
particular prolonged bouts of sedentary behaviour. In Australia, guidelines for safety at work recommend taking a break from sitting at least every $30 \mathrm{~min}$ [11]. Importantly, the health risks from prolonged sedentary behaviour are independent of the risks associated with recommended levels of moderate to vigorous physical activity $[15,19]$. In this article we use two complementary frameworks for identifying the opportunities and constraints for increasing physical activity to help office workers meet physical activity guidelines: Social ecological models and the COM-B framework [20-22].

\section{Social ecological model}

Social ecological models have been widely used in health promotion since the 1980 's but only more recently for understanding the correlates of physical activity [21, 23, 24]. The value of using social ecological models is the holistic approach which identifies the agency of social, cultural, and environmental factors on health behaviours [22]. Social ecological models have proven to be an effective framework for understanding and guiding population-based health behaviour change interventions [22, 25-27]. Social ecological models reveal the multidimensional, multi-level, often nested layers of context $[21,28]$, the complexities of which are well explained in Stokols [25]. Levels of agency in social ecological models range from the individual to global, and dimensions include both socio-cultural and physical or environmental factors $[27,29]$.

Social ecological models can also be scaled down to focus on specific settings and contexts $[23,30]$. Health settings are defined as "the place or social context in which people engage in daily activities in which environmental, organisational and personal factors interact to affect health and wellbeing" [31] [32]. The settings approach is a social ecological model developed for informing public health promotion and policy [30,32]. The specificity and predictive capacity of social ecological models can be improved if research based on social ecological models focuses on both specific behaviours and specific contexts $[23,33]$. Context refers to the locale or environment in which physical activity occurs, because people behave differently in different circumstances [23, 33]. This more targeted context-based approach can provide a better understanding of the interrelationships between the diverse correlates of physical activity and differences in the performance of specific behaviours in context [33]. The advantages of targeted context-based research is that it can have sustained impact because changes to the environment can be more enduring and can affect more than individual behaviour [23]. The growing interest in physical activity as a preventative health measure has given rise to ecological models which focus on the context of physical activity [21].

\section{COM-B framework}

While the purpose of social ecological models is to understand the broad range of agency and factors contributing to health and wellbeing, $\mathrm{COM}-\mathrm{B}$ provides a framework for behaviour change. Michie et al's COM-B framework identifies the three key mechanisms of behaviour change as: motivation, capability and opportunity [20]. Motivation is viewed as an expression of an individual's desire to perform an activity or to change behaviour whereas capability describes an individual's capacity to perform an activity or to change behaviour which includes having the necessary physical ability, knowledge and skills. Opportunity captures external factors that enable or motivate behaviour which includes changes to the physical environment and social opportunities [20]. COM-B can add to the understanding of the mechanisms of behaviour change in social ecological models [20, 21, 27].

\section{Aims and methods}

This paper draws on the literature on physical activity and sedentary behaviour to develop a social ecological model targeting office-based work and uses the COM-B framework to propose the mechanisms of behaviour change identified in the model. COM-B refers to capability, opportunity and motivation as the three conditions essential for behaviour change [20]. Social ecological models are complex nested models with individuals at the very centre. Individual factors include demographics, biological, psychological and family situation [21]. In this paper, we focus predominantly on context in developing the social ecological model as there is already a large body of work on the individual correlates of behaviour change [27, 29, 34, 35].

The first step in the development of a social ecological model for a specific context and a specific behaviour is the conceptualisation [36], involving a reflective process considering the factors involved, guided by the work of Sallis et al. and Giles-Corti et al. [21-23]. In this process, we scoped the extant literature on work and office-based physical activity and sedentary behaviour to conceptualise a social ecological model of office-based physical activity. We used a structured approach that focused on two different dimensions, the physical environment and the socio-cultural environment [23]. The nested nature of social ecological models involves consideration of multiple levels of agency from macro to micro. To build the model we scoped papers on physical activity/sedentary behaviour at work including activity associated with office work tasks, commuting and work break, and lunchtime activities. We included papers on the impact of the physical dimensions of office work settings, including the natural environment, the built environment, building design and ergonomics. For the social cultural 
dimension, we included papers on office policy and organisational and socio-cultural factors. To highlight the mechanisms of behaviour change inherent in the model, the first two named authors jointly mapped the model against the COM-B framework. Differences were resolved through discussion.

\section{Proposed social ecological model for office-based work}

In social ecological models there are five domains of human activity; work, recreation, transport, household activities and sleep. The work domain is unique in that individuals have less personal agency. The physical activity of office workers is largely determined by the social, cultural and physical context of the workplace [37].

In the following sections we discuss the socio-cultural and physical dimensions of office-based work guided by frameworks developed by Sallis et al. and Giles-Corti et al. [21, 23] to propose a social ecological model for the specific context of office-based work using COM-B framework to highlight opportunity, capability and motivation. Both the dimensions of the ecological model and the COM-B mapping are summarised in Fig. 1.

\section{Socio-cultural dimensions.}

Employment involves a contractual agreement stating employment conditions, outlining the rights, responsibilities and duties of employees. Employment and officebased work are complex socio-cultural constructs which include legal, mandatory and voluntary frameworks and workplace cultural practices such as unspoken expectations about how many hours we work a day. It also includes interactions with colleagues and social networks such as who we work with and with whom we share our breaks. In this section we look at three socio-cultural dimensions of office-based physical activity, ranging from macro to micro: policy, organisational, socio-cultural.

\section{Policy environment}

The political dimension of physical activity at work includes both mandatory frameworks for physical activity at work, such as workplace health and safety legislation, and voluntary frameworks such as policy, guidelines and best practice.

Mandatory frameworks that cover physical activity at work include federal or state legislation on health and safety at work. Legislation imposes responsibility and liability on organisations and workplaces [38]. Workplace health and safety law regulates the maximum number of hours worked, entitlement to rest breaks and rest days. Legislation impacts behaviour at work by regulating work hours to allow workers the opportunity to recover from the cumulative effect of work on both physical and mental health.
Voluntary frameworks include policy and guidelines. Policy at various levels from national and state level provide frameworks and guidance which impact organisations in different ways. For example, the use of incentives or tax rebates to encourage physical activity at work [38] create capability and opportunity for physical activity at work.

Increasing physical activity can also be achieved indirectly through changes in the built environment. Zoning changes can indirectly increase levels of physical activity [39]. Policy that impacts the built environment may result in improved attractiveness of outdoor spaces and more opportunities for physical activity around office buildings. These could include: changes in land use, zoning and access to public transport, support for active transport, improved street lighting and reduced traffic flow [38], changes which also impact capability and motivation to engage in physical activity in or around workplaces.

Guidelines on physical activity at work are published at many levels by statutory, non-statutory and advisory bodies. Such guidelines provide direction and information for employers and employees reflecting current best practice based on emerging research. Guidance provided to employers and employees impacts capability and motivation for physical activity through education and information about the benefits of physical activity at work.

\section{Organisational factors}

Employers control the nature of the work undertaken, the environment in which the work takes place, the number of hours worked, the time frame during which the hours are to be worked. All these, along with the nature of the occupation are key determinants of office-based physical activity at work. Seventy two percent of Australian jobs are in the service sector [40]. Changes in occupation impact the opportunity for physical activity at work. Growth in the proportion of service sector jobs over the last 50 years have resulted in population wide reductions in average daily occupation related energy expenditure and weight gain in the U.S. [41]. Research from the Netherlands also found that occupation determines the amount of sitting time. People working in computerisation, commercial services, transportation, banking insurance and government and judicial organizations sat significantly longer than the average worker [42].

Non-discretionary physical activity (read also inactivity) is dictated by job role, organisational practice and workplace culture $[43,44]$. Full time office workers are expected to work $\pm 7 \mathrm{~h}$ a day, predominantly sitting at a desk. Sedentary time at work adds to daily sedentary behaviour totals to increase the risk of disease associated with sedentary behaviour. For a fulltime worker, time spent at work comprises around $27 \%$ of waking hours a 


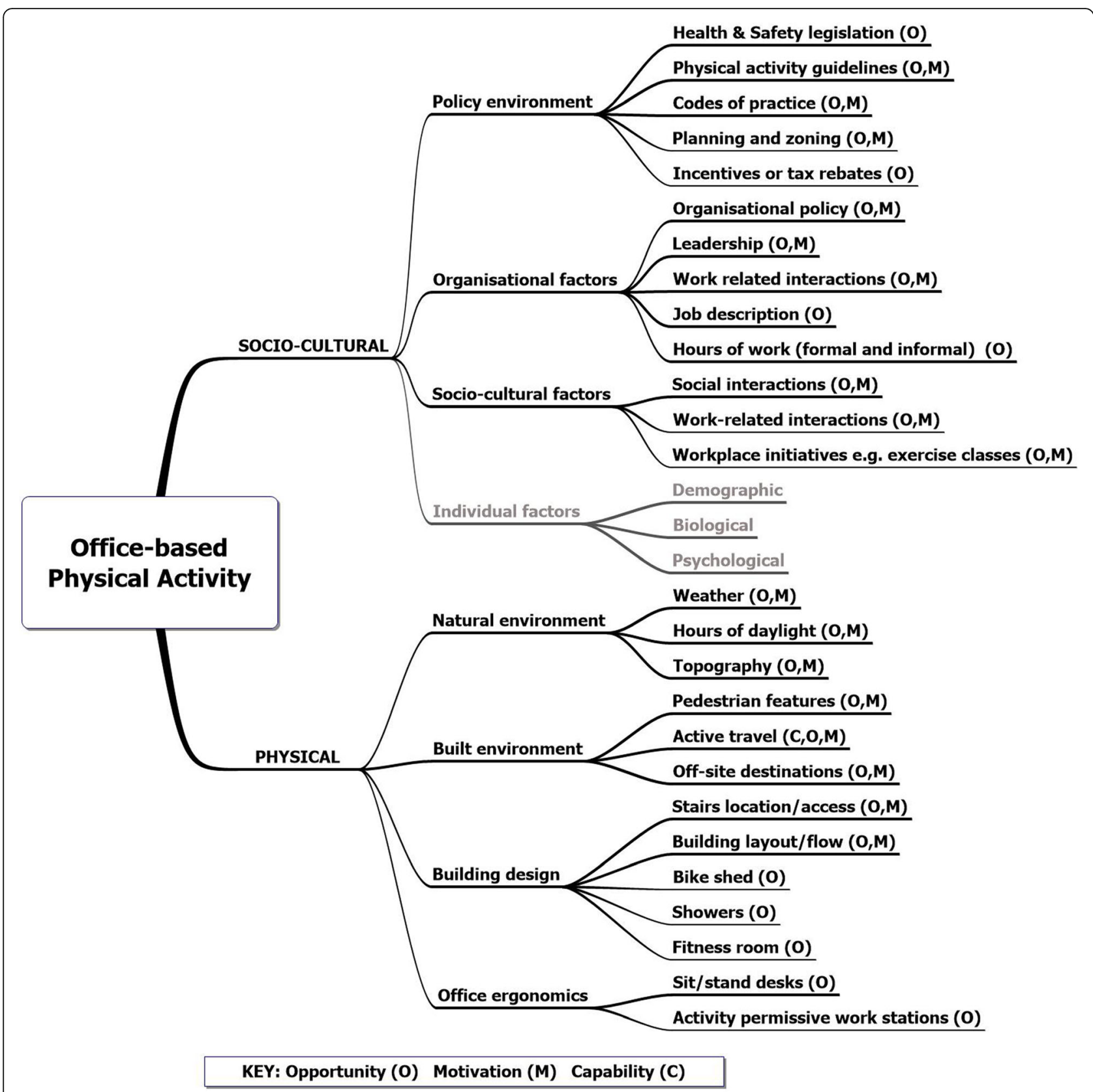

Fig. 1 Social ecological model of office-based physical activity mapped to COM-B. Individual factors in the model come from Sallis et al. [21]

year, assuming $7 \mathrm{~h}$ a day at work. If you add in time spent commuting to work in cars or seated on public transport, then the proportion of time spent in sedentary behaviour increases again. Research comparing office, customer service, and call centre workers showed that call centre workers were both the most sedentary and spent more time in prolonged bouts of sedentary behaviour, than either office workers of customer services workers with customer service workers being the least sedentary of the three [14].
Organisations and workplaces not only have an obligation under law to provide for the safety and wellbeing of their employees, but they have a vested interest in reducing sick leave, productivity loss, workers compensation and disability management costs $[45,46]$. At the corporate level, voluntary frameworks start with corporate health policy. Top down health policies provide the necessary framework, motivation and opportunity to unlock funding for physical activity initiatives and the motivation for workplaces to initiate and maintain 
corporate physical activity programs at work. Key strategies for successful corporate health policies include creating site specific health policies, thinking long term, having clear priorities, being consistent, communicating strategically, ensuring adequate resources, demonstrating leadership, engaging middle management, promoting employee participation, using incentives and awards and promoting active commuting [47]. Corporate policy is also an important enabler of capability for physical activity at work, through education and promotion, signage and awareness raising.

\section{Socio-cultural factors}

Socio-cultural support for office-based physical activity can build on the foundations of organisational health policy and health and safety at work, because to be effective, changes in safe work practices have to become an integral part of workplace culture [48]. The sociocultural dimension of physical activity at work can support capability and motivation to engage in physical activity through health promotion, education, newsletters, signage, bulletin boards or initiatives such as corporate challenges and health promotion $[49,50]$. Socio-cultural support for physical activity at work can also be achieved through leadership and example. Workers who perceived their co-workers and their managers as being physically active were more likely to be physically active at work [51]. Workplace culture can also negatively affect physical activity at work. It not uncommon for companies to have an unspoken culture of working late. Long working hours contribute to daily totals of sedentary behaviour and negatively impact workers health [52-54]. Another reason people move about an office is to talk to colleagues. A recent study in which office workers were relocated to a new building showed that expectations of quietness in the new building discouraged short non sedentary breaks in workflow occasioned by getting up to talk to colleagues or standing about having casual chats at colleagues' desk [55].

\section{Physical dimensions}

In general the physical dimensions, the setting of the physical activity, are less well researched [23]. This is less true for physical activity at work because of employer responsibilities under health and safety regulations and growing concerns over the negative health impacts of occupational sedentary behaviour. In this section we describe four different physical dimensions of office-based settings from micro to macro: ergonomics, building design and layout, the built environment and the natural environment.

\section{Ergonomics}

Research advises breaks from sitting every 30 min to reduce the risk of adverse health outcomes [56], however, the optimal duration of breaks in sedentary time or recommended activity (standing or sitting) during breaks is unknown. A commonly used cut point for breaks is a minimum duration of $1 \mathrm{~min}$, a pragmatic option rather than one grounded in research [56, 57]. One minute breaks comprising a minimum of 50 movements per minute in the Diaz study and 100 movements/minute in the Healy study were beneficial in reducing all-cause mortality [56] waist circumference, BMI and triglycerides and 2-h plasma glucose [57]. Another study found that 2 min breaks that included light intensity exercise was better for cardio metabolic health than 2 min breaks that involved just standing which was no different to uninterrupted sitting [58]. Ergonomics has led to improvements in the design of office chairs and sit-stand desks to reduce the adverse impact of prolonged sedentary behaviour [59]. Sit-stand desks provide workers with the opportunity to reduce sedentary behaviour with standing breaks, however, to date the evidence of the effectiveness of activity permissive workstation (sit-stand desks, treadmill desks, etc.) is mixed. Chau et al. found that none of the 6 studies they reviewed showed significant differences in sedentary behaviour between intervention and control groups and MacEwen et al. found that while treadmill desks improved postprandial glucose, HDL cholesterol, and anthropometrics, sit-stand desks resulted in few changes [2,60]. Similarly, a meta-analysis of activity permissive work stations showed a significant overall reduction in sedentary time of $77 \mathrm{~min}$ over an $8 \mathrm{~h}$ working day but non-significant results for health and work related outcomes [61].

\section{Building design and layout}

There has been little research on the impact of building design on physical activity and sedentary behaviour of office workers [55, 62]. Building design and floor layout can indirectly shape the organisation of work and the opportunities for incidental physical activity at work [63]. Incidental physical activity occurs in the completion of everyday tasks. In the office, incidental activity is typically short duration trips to and from communal facilities such as kitchens, bathrooms, printers, and meeting rooms [55, 64-66]. The amount of incidental activity a worker accrues in a work day depends largely on a worker's desk location in relation to communal facilities.

Opportunities for physical activity at work can also be hardwired into the building design through the provision of facilities such as bike sheds, showers and a gym or space that can be used for exercise classes. Stairs are also an opportunity for including MVPA in daily work routines, however, importantly, the placement and visibility of the stairs relative to the ways in which people use space and move through the building impacts motivation, because convenience and efficiency are key 
considerations $[55,65]$. The importance of stairwell placement is illustrated in a pre/post study of a workplace relocation. Office workers moved from one building to a purposed designed new building which resulted in a small but significant decrease in stair use attributable to change in stair placement and functionality and lack of connectivity between floors [55].

\section{Built environment}

The built environment surrounding the workplace is important for creating opportunities for sustained bouts of physical activity and potentially MVPA. Current guidelines recommend a minimum duration of movement of 10 min, which would be difficult to achieve inside a building [16-18]. The built environment determines opportunity and motivation for outdoor physical activity, influencing available commuting options, off-site destinations and pedestrian features. A recent systematic review showed that adult physical activity was significantly related to street/pedestrian connectivity and the proximity of non-recreational land use (cafes, shops, restaurants) [67]. Commuting, though not strictly work related, is nonetheless a non-discretionary activity associated with work unless you work from home. Long commutes to work can also add to daily sedentary behaviour however, commuting is also an opportunity for incidental physical activity, if only the walk from the car park or bus stop to the office. The built environment and local planning are big factors in determining the opportunities and capability for walking and cycling to work. Safety and ease of active transport options such as walking or cycling to work, proximity of public transport and car parks are all determinants of physical activity through commuting [68-70].

The presence of off-site destinations such as shops, food outlets, gardens or parks also provide both opportunity and motivation for physical activity during breaks at work. Research showed that the presence of offsite destinations within a radius of $800 \mathrm{~m}$ increases distance walked while at work [71] by affording opportunities for non-work related incidental physical activity such as going out for lunch or shopping [64]. Motivation to use outdoor space is also determined by pedestrian features such as footpaths and benches which can make open outdoor spaces more attractive and good lighting and traffic calming which can make walking safer [64].

\section{Natural environment}

Very few studies of physical activity account for climate or weather as separate variables, or even report, temperature or precipitation over the course of the data collection [33]. Changes in weather have most impact on discretionary behaviour and in particular motivation for MVPA. Understanding more about how climate and weather impacts the use of outdoor spaces at work is important [72, 73]. A systematic review of the effects of weather and seasonality on physical activity found that weather and seasonality are correlates of physical activity $[33,74]$. To the best of our knowledge there is no research on the impact of weather on physical activity at work, but weather is likely to impact motivation for use of outdoor spaces while commuting and during work hours. There are a few studies showing the impact of weather on commuting. As might be expected, precipitation, temperature extremes and wind had significant impact on cycling to work [75, 76]. A study of student commuting also found that shortened daylight hours negatively affected cycle commuting [77].

Topography of the local environment can also influence motivation, opportunities and capability for MVPA. Hilly or steep precincts provide more incidental MVPA but may also impact capability and motivation to walk during breaks or active transport to work options such as walking and cycling. While there is little evidence of the impact of topography on physical activity at work, it has been found that hilly environments negatively impact on cycling and walking for household activities that could be reasonably walked or cycled and which did not involve carrying items (e.g. shopping) [78]. Rodríguez and Joo [79] found that, for students and staff of the University of North Carolina in Chapel Hill, slope negatively impacted propensity to walk or cycle. Similarly, other studies have found that hills have an overall negative impact of commuter cycling, but they are more appealing to experienced cyclists $[80,81]$. While topography is not something that can change it nonetheless contributes to how people engage with active transport locally and it's a factor that needs to be considered if research is being done across multiple sites.

\section{Linking office-based physical activity opportunities to physical activity guidelines}

Both the physical and socio-cultural dimensions combine to provide opportunities for physical activity at work. Table 1 summarises the opportunities against the current physical activity guidelines focussing highlighting the largely discretionary nature of physical activity in office-based settings.

\section{Conclusions}

High levels of sedentary behaviour associated with allcause mortality and chronic disease morbidity are now endemic in developed countries. Sedentary behaviour at work is a contributing factor given that on working days, half our waking hours are spent at work. Growth in service sector and computer-based employment combined with the rising age of retirement in developed countries are set to increase occupational sedentary behaviour and 
Table 1 Mapping aspects of the office physical environment to current physical activity guidelines

\begin{tabular}{|c|c|c|c|c|c|}
\hline Duration & Intensity & Location & Intention & Activity/ context & Description \\
\hline Short & Light & Desk & Incidental & Standing & $\begin{array}{l}\text { Sit-stand desk, talking to colleagues, printing, } \\
\text { filing, standing whilst talking on the phone }\end{array}$ \\
\hline Medium & Light & Desk & Discretionary & Standing & Sit-stand desk \\
\hline Short & Light & Office Building & Incidental & Walking & $\begin{array}{l}\text { Walking short distances (stop/start): Trips to } \\
\text { and from bathroom, kitchen meeting rooms }\end{array}$ \\
\hline Short/ Medium & Light & Precinct, Neighbourhood & Incidental & Commuting & Walk to car park or transit point \\
\hline Medium/ Long & $\begin{array}{l}\text { Light } \\
\text { MVPA }\end{array}$ & Precinct, Neighbourhood & Discretionary & Commuting & Walking to work ${ }^{\mathrm{a}}$ \\
\hline Medium/ Long & MVPA & Precinct, Neighbourhood & Discretionary & Commuting & Cycling to work ${ }^{a}$ \\
\hline Short & MVPA & Building & Incidental & Climbing stairs & $\begin{array}{l}\text { Using the stair as an efficient way for getting } \\
\text { from } A \text { to } B\end{array}$ \\
\hline Short/ Medium & MVPA & Building & Discretionary & Climbing stairs & Using the stair for increasing PA \\
\hline Medium & MVPA & Building & Discretionary & Gym & Gym, exercise classes, jogging \\
\hline Medium & $\begin{array}{l}\text { Light } \\
\text { MVPA }\end{array}$ & Precinct, neighbourhood & Discretionary & Brisk walking & Walking breaks, walking groups \\
\hline Medium & Light & Precinct, Neighbourhood & Discretionary & Work breaks & $\begin{array}{l}\text { Walks out doors during breaks, walking to } \\
\text { local shops and cafes, restaurants }\end{array}$ \\
\hline
\end{tabular}

aLocal area (reasonable cycling distance 32 min - walking 22 min for FT worker [82]

the associated risks. In this article, in line with guidelines on physical activity which recommend both daily/weekly targets of MVPA as well as reduction in sedentary behaviour and especially prolonged sedentary behaviour, we reviewed socio-cultural and physical factors impacting physical activity for office-based workers to develop a social ecological model to inform interventions aimed at reducing sedentary behaviour and increasing physical activity for office workers. We then mapped each option against the COM-B framework to identify the underpinning mechanisms of behaviour change (opportunity, capability and motivation).

Behaviour change is a focal element of many interventions to increase physical activity, however, research into public health interventions has shown that a broader approach based on social ecological models is more successful than targeting individual behaviour alone $[25,83]$. This is particularly true for physical activity at work because of the non-discretionary nature of sedentary behaviour of office workers. The organisation and the workplace largely determine the capability, opportunity and motivation for physical activity at work. A systematic review comparing the effectiveness of different types of interventions found that interventions that included organisational (e.g. steering committees, senior management endorsement, action days and gymnastics breaks) and environmental elements (e.g. signage, maps, staircase promotion, walking tracks) reported better results than interventions which focussed on behavioural change and information only [84].

This paper contributes to the literature by proposing a context specific social ecological model for office-based work aimed at reducing sedentary behaviour and enhancing physical activity [23] and identifying the mechanisms for behaviour change inherent in the resulting social ecological model. The model can help inform the development of more complex and context specific work place interventions to reduce sedentary behaviour and increase physical activity for office-based workers.

Being more inclusive of a range of different factors involved in measuring change or monitoring physical activity in office-based setting is a challenge for the collection of data, however, the field of physical activity research is changing. The last decade has seen the use of research grade accelerometers being used to measure physical activity and more particularly sedentary behaviour of office workers. Data collection is typically around 7 days $[6,7,62]$. A recent study by Mullane et al. [85] investigated the social ecological correlates of sedentary using ActivPAL inclinometers (7 days) and two online surveys. Results showed that physical activity was positively related to lunchtime walking and that talking to colleagues was negatively correlated with prolonged sitting. Furthermore, open plan or shared offices were less associated with prolonged sitting than private offices.

Advances in technology and connectivity present new opportunities for understanding physical activity in context-based on growth in consumer wearables, use of mobile phones and the internet of things (IOT), devices which can be used to collect data from individuals and the environment.

First, the improved reliability and accuracy of consumer activity trackers means that these relatively low cost devices are increasingly being used for longitudinal research to understand physical activity in free living environments with large sample sizes over longer periods of time [86-88]. The collection of big data on physical 
activity opens opportunities for research that can investigate how for example, job descriptions, seniority or socio-demographic factors impact incidental and discretionary physical activity at work. Longitudinal temporal data also allows researchers to develop profiles of how physical activity is distributed over time to understand patterns of behaviour [14, 33, 88, 89]. Understanding how physical activity is distributed over time is very relevant to research on physical activity at work. Timing of breaks in sedentary behaviour is important for achieving health benefits of sit-stand desks and other behaviour change designed to reduce the length of bouts of sedentary behaviour. Work activities are time sensitive, so it is important to understand because opportunities for physical activity are largely regulated by workplace organisation and culture such as hours of work and timing of meetings and breaks.

Second, the ubiquity of mobile phones and the growth in the IOT will facilitate the collection of contextual data to supplement data from consumer activity trackers [88]. While the use of contextual data to add to the understanding of physical activity is still new [33, 88], increasingly global positioning systems (GPS) and other environmental sensors are being used to track movement [90]. One of the issues with research on changes in infrastructure or the built environment is the difficulty of measuring and evaluating change [91]. The addition of environmental and location data with data from smart phones or commercial activity trackers can create new insights into how context influences physical activity $[88,92,93]$ and can help inform workplace design and changes to the built environment to better facilitate both incidental and discretionary physical activity. It is also possible to use data from activity trackers and the IOT to profile or rate buildings based on the opportunities for physical activity for specific buildings and the local built environment, to understand more about designing activity permissive office environments [eg. 62].

The collection of digital data on physical activity and context using consumer activity trackers, mobile phones and sensors in the environment can lead to the creation of large datasets or big data. Big data with high levels of granularity can address different research questions [87, 94-96], however it can also change the nature of research which is likely to become more multi-disciplinary given the new challenges of data storage, management and analysis.

Social ecological models and COM-B together, draw attention to the dynamic interplay of factors both sociocultural and physical that can contribute to facilitating behaviour change to increase physical activity at work. The social ecological model is a useful framework for thinking holistically about physical activity in office-based settings to guide the design and collection of contextual data and inform different research questions [21, 27, 97]. To increase levels of physical activity in office-based settings, it is important for interventions not to rely as strongly on individual motivation for behaviour change but to incorporate changes to the broader social ecological and physical context to build capability and create opportunities for more sustainable change.

\section{Abbreviations}

COM-B: Capability motivation opportunity - behaviour; GPS: Global positioning system; IOT: Internet of things; METs: Metabolic equivalents; MVPA: Moderate to vigorous physical activity

\section{Acknowledgements}

Not applicable.

\section{Authors' contributions}

The ecological model for physical activity at work was conceptualised and developed by YvK. LKL provided critical feedback on the model and mapping the model to the behaviour change wheel and AM and LKL provided critical revision of the manuscript and approved the final version. All authors read and approved the final manuscript.

\section{Authors' information}

Not applicable.

Funding

Not applicable.

Availability of data and materials

Not applicable.

Ethics approval and consent to participate

Not applicable.

Consent for publication

Not applicable.

\section{Competing interests}

The authors declare that they have no competing interests.

\section{Author details}

${ }^{1}$ Flinders Digital Health Research Centre, Flinders University, GPO Box 2100, Adelaide, South Australia 5001, Australia. ${ }^{2}$ Caring Futures Institute, College of Nursing and Health Sciences, Flinders University, GPO Box 2100, Adelaide,

South Australia 5001, Australia.

Received: 27 September 2018 Accepted: 27 January 2020 1.

\section{References}

1. Sedentary Behaviour Research N. Letter to the Editor: Standardized use of the terms "sedentary" and "sedentary behaviours". Appl Physiol Nutr Metab. 2012;37(3):540-2.

2. Chau JY, der Ploeg HP, van Uffelen JG, Wong J, Riphagen I, Healy GN, Gilson ND, Dunstan DW, Bauman AE, Owen N, et al. Are workplace interventions to reduce sitting effective? A systematic review. Prev Med. 2010;51(5):352-6.

3. Maher CG. A systematic review of workplace interventions to prevent low back pain. Aust J Physiother. 2000;46(4):259-69.

4. van Uffelen JG, Wong J, Chau JY, van der Ploeg HP, Riphagen I, Gilson ND, Burton NW, Healy GN, Thorp AA, Clark BK, et al. Occupational sitting and health risks: a systematic review. Am J Prev Med. 2010;39(4):379-88.

5. Bockermann $P$, Johansson $E$, Jousilahti $P$, Uutela A. The physical strenuousness of work is slightly associated with an upward trend in the BMI. Soc Sci Med. 2008:66(6):1346-55.

6. Parry S, Straker L. The contribution of office work to sedentary behaviour associated risk. BMC Public Health. 2013;13:296.

7. Clemes SA, O'Connell SE, Edwardson CL. Office workers' objectively measured sedentary behavior and physical activity during and outside working hours. J Occup Environ Med. 2014;56(3):298-303. 
8. Owen N, Healy GN, Matthews CE, Dunstan DW. Too much sitting: the population health science of sedentary behavior. Exerc Sport Sci Rev. 2010; 38(3):105-13.

9. Kuoppala J, Lamminpää A, Husman P. Work health promotion, job wellbeing, and sickness absences - a systematic review and meta-analysis. J Occup Environ Med. 2008:50(11):1216-27.

10. Owen N, Sparling PB, Healy GN, Dunstan DW, Matthews CE. Sedentary behavior: emerging evidence for a new health risk. Mayo Clin Proc. 2010; 85(12):1138-41.

11. Straker L, Dunstan D, Gilson N, Healy G. Sedentary work - evidence on an emergent work health and safety issue - final report. In., vol. 2020 Canberra: Safe Work Australia; 2016

12. Bauman A, Ainsworth BE, Sallis JF, Hagstromer M, Craig CL, Bull FC, Pratt M, Venugopal K, Chau J, Sjostrom M, et al. The descriptive epidemiology of sitting. A 20-country comparison using the international physical activity questionnaire (IPAQ). Am J Prev Med. 2011;41(2):228-35.

13. Katzmarzyk PT, Church TS, Craig CL, Bouchard C. Sitting time and mortality from all causes, cardiovascular disease, and cancer. Med Sci Sports Exerc. 2009;41(5):998-1005.

14. Thorp AA, Healy GN, Winkler E, Clark BK, Gardiner PA, Owen N, Dunstan DW Prolonged sedentary time and physical activity in workplace and non-work contexts: a cross-sectional study of office, customer service and call Centre employees. Int J Behav Nutr Phys Act. 2012;9:128.

15. Thorp AA, Owen N, Neuhaus M, Dunstan DW. Sedentary behaviors and subsequent health outcomes in adults a systematic review of longitudinal studies, 1996-2011. Am J Prev Med. 2011;41(2):207-15.

16. Australian Government Department of Health. Make your move - sit less Be active for life! In: Austrlaia's Physical activity and sedentary behevaiour guidelines for adults (18-64 years). Canberra: Australian Government; 2017 https://www.google.com/search?q=Make+your+move+-+sit+less+-+Be+ active+for+life!\&rlz=1C1GGRV_enAU751AU751\&oq=Make+your+move+-+ sit+less+-+Be+active+for+life!\&aqs=chrome..69i57j0l3.4319j0j4\&sourceid= chrome\&ie=UTF-8. Accessed 24 Jan 2020.

17. 2018 Physical Activity Guidelines Advisory Committee: Scientific Report. In United States; 2018. https://health.gov/paguidelines/second-edition/report/. Accessed 24 Jan 2020

18. UK Department of Health: Physical activity guidelines for adults (19 to 64 years). 2017. https://www.nhs.uk/Livewell/fitness/Documents/adults-19-64years.pdf. Accessed 24 Jan 2020.

19. de Rezende LF, Rodrigues Lopes M, Rey-Lopez JP, Matsudo VK, Luiz Odo C. Sedentary behavior and health outcomes: an overview of systematic reviews. PLoS One. 2014;9(8):e105620.

20. Michie S, van Stralen MM, West R. The behaviour change wheel: a new method for characterising and designing behaviour change interventions. Implement Sci. 2011;6(1):42

21. Sallis JF, Cervero RB, Ascher W, Henderson KA, Kraft MK, Kerr J. An ecological approach to creating active living communities. Annu Rev Public Health. 2006;27:297-322

22. Sallis JF, Owen N, Fisher E. Ecological models of health behavior. In: Glanz K, Rimer B, Viswanath K, editors. Health behavior: theory, research, and practice. 5th ed. San Francisco: Jossey-Bass; 2015. p. 43-64.

23. Giles-Corti B, Timperio A, Bull F, Pikora T. Understanding physical activity environmental correlates: increased specificity for ecological models. Exerc Sport Sci Rev. 2005;33(4):175-81.

24. Richard L, Gauvin L, Raine K. Ecological models revisited: their uses and evolution in health promotion over two decades. Annu Rev Public Health. 2011;32:307-26.

25. Stokols D. Establishing and maintaining healthy environments: toward a social ecology of health promotion. Am Psychol. 1992:47(1):6.

26. Stokols D. Translating social ecological theory into guidelines for community health promotion. Am J Health Promot. 1996;10(4):282-98,

27. Bauman A, Reis RS, Sallis JF, Wells JC, Loos RJF, Martin BW. Correlates of physical activity: why are some people physically active and others not? Lancet. 2012;380(9838):258-71.

28. Bronfenbrenner U. Toward an experimental ecology of humandevelopment. Am Psychol. 1977;32(7):513-31.

29. Trost SG, Owen N, Bauman AE, Sallis JF, Brown W. Correlates of adults' participation in physical activity: review and update. Med Sci Sports Exerc. 2002;34(12):1996-2001.

30. Dooris M. Healthy settings: challenges to generating evidence of effectiveness. Health Promot Int. 2006;21(1):55-65.
31. World Health Organization. Health promotion glossary in. Geneva: World Health Organization; 1998. https://www.who.int/healthpromotion/about/ HPG/en/. Accessed 24 Jan 2020

32. Dooris M. Joining up settings for health: a valuable investment for strategic partnerships? Crit Public Health. 2004;14(1):49-61.

33. Humpel N, Owen N, Leslie E. Environmental factors associated with adults' participation in physical activity: a review. Am J Prev Med. 2002;22(3):188-99.

34. O'Donoghue G, Perchoux C, Mensah K, Lakerveld J, van der Ploeg H, Bernaards C, Chastin SFM, Simon C, O'Gorman D, Nazare J-A. A systematic review of correlates of sedentary behaviour in adults aged 18-65 years: a socio-ecological approach. BMC Public Health. 2016;16(1):163.

35. Smith L, McCourt O, Sawyer A, Ucci M, Marmot A, Wardle J, Fisher A. A review of occupational physical activity and sedentary behaviour correlates. Occup Med. 2016;66(3):185-92.

36. Sallis JF, Bauman A, Pratt M. Environmental and policy interventions to promote physical activity. Am J Prev Med. 1998;15(4):379-97.

37. Quintiliani L, Sattelmair J, Sorensen G: The workplace as a setting for interventions to improve diet and promote physical activity. Background paper prepared for the WHO/WEF Joint Event on Preventing Noncommunicable Diseases in the Workplace (Dalian/ China, September 2007). http://www.who.int/dietphysicalactivity/Quintiliani-workplace-assetting.pdf. Acccessed 24 Jan 2020.

38. King A, Jeffery RW, Fridinger F, Dusenbury L, Provence S, Hedlund SA, Spangler K. Environmental and policy approaches to cardiovascular disease prevention through physical activity: issues and opportunities. Health Educ Q. 1995;22(4):499-511.

39. Leider J, Chriqui JF, Thrun E. Associations between active living-oriented zoning and no adult leisure-time physical activity in the U.S. Prev Med. 2017;95(Suppl):S120-5

40. Australian Government. Ecomomic conditions. In: Australian industry report 2016. Canberra: Department of Industry Innovation and Science; 2016. https://publications.industry.gov.au/publications/australianindustryreport/ assets/Australian-Industry-Report-2016.pdf. Accessed 24 Jan 2020

41. Church TS, Thomas DM, Tudor-Locke C, Katzmarzyk PT, Earnest CP, Rodarte RQ, Martin CK, Blair SN, Bouchard C. Trends over 5 decades in U.S. occupation-related physical activity and their associations with obesity. PLoS One. 2011;6(5):e19657

42. Jans MP, Proper Kl, Hildebrandt VH. Sedentary behavior in Dutch workers: differences between occupations and business sectors. Am J Prev Med. 2007;33(6):450-4.

43. Zisberg A, Young HM, Schepp K, Zysberg L. A concept analysis of routine: relevance to nursing. J Adv Nurs. 2007;57(4):442-53.

44. Becker MC. Organizational routines: a review of the literature. Ind Corp Chang. 2004;13(4):643-78.

45. Comcare. Benefits to Business: The evidence for investing in worker health and wellbeing. Canberra: Australian Government; 2011. https://www. comcare.gov.au/Forms_and_Publications/publications/services/safety_and prevention/safety_and_prevention/bene_to_busin_the_evid_for_invest_in work health wellbeing. Accessed 24 Jan 2020

46. Buckley JP, Hedge A, Yates T, Copeland RJ, Loosemore M, Hamer M, Bradley G, Dunstan DW. The sedentary office: a growing case for change towards better health and productivity. Expert statement commissioned by Public Health England and the active working community interest company. $\mathrm{Br}$ Sports Med. 2015;49(21):1357-62.

47. Pronk NP, Kottke TE. Physical activity promotion as a strategic corporate priority to improve worker health and business performance. Prev Med. 2009;49(4):316-21.

48. DeJoy DM. Behavior change versus culture change: divergent approaches to managing workplace safety. Saf Sci. 2005;43(2):105-29.

49. Oldenburg B, Sallis JF, Harris D, Owen N. Checklist of health promotion environments at worksites (CHEW): development and measurement characteristics. Am J Health Promot. 2002;16(5):288-99.

50. Jirathananuwat A, Pongpirul K. Promoting physical activity in the workplace: a systematic meta-review. J Occup Health. 2017:59(5):385-93.

51. Bennie J, Timperio A, Dunstan D, Crawford D, Salmon J. Environmental correlates of physical activity in Australian workplaces. Int J Workplace Health Manag. 2010;3(1):25-33.

52. Kirk MA, Rhodes RE. Occupation correlates of adults' participation in leisuretime physical activity: a systematic review. Am J Prev Med. 2011;40(4):476-85.

53. Sparks $K$, Cooper $C$, Fried $Y$, Shirom A. The effects of hours of work on health: a meta-analytic review. J Occup Organ Psychol. 2011;70(4):391-408. 
54. Spurgeon A, Harrington JM, Cooper CL. Health and safety problems associated with long working hours: a review of the current position. Occup Environ Med. 1997;54(6):367.

55. Creagh R, McGann S, Tye M, Jancey J, Babb C. Green star is not a physical activity star. Facilities. 2017;35(1):81-98.

56. Diaz KM, Howard VJ, Hutto B, Colabianchi N, Vena JE, Safford MM, Blair SN, Hooker SP. Patterns of sedentary behavior and mortality in U.S. middle-aged and older adults: a National Cohort Study. Ann Intern Med. 2017;167(7):465-75.

57. Healy GN, Dunstan DW, Salmon J, Cerin E, Shaw JE, Zimmet PZ, Owen N. Breaks in sedentary time: beneficial associations with metabolic risk. Diabetes Care. 2008;31(4):661-6.

58. Bailey DP, Locke CD. Breaking up prolonged sitting with light-intensity walking improves postprandial glycemia, but breaking up sitting with standing does not. J Sci Med Sport. 2015;18(3):294-8.

59. Pheasant S. Bodyspace: anthropometry, ergonomics and the design of work 3rd ed. Boca Raton: CRC Press; 2014

60. MacEwen BT, MacDonald DJ, Burr JF. A systematic review of standing and treadmill desks in the workplace. Prev Med. 2015;70:50-8.

61. Neuhaus M, Eakin EG, Straker L, Owen N, Dunstan DW, Reid N, Healy GN Reducing occupational sedentary time: a systematic review and metaanalysis of evidence on activity-permissive workstations. Obes Rev. 2014 15(10):822-38

62. Gorman E, Ashe MC, Dunstan DW, Hanson HM, Madden K, Winkler EA McKay HA, Healy GN. Does an 'activity-permissive'workplace change office workers' sitting and activity time? PLoS One. 2013;8(10):e76723.

63. Lee H, Sawyer S. Conceptualizing time, space and computing for work and organizing. Time Soc. 2010;19(3):293-317.

64. Zimring C, Joseph A, Nicoll GL, Tsepas S. Influences of building design and site design on physical activity. Am J Prev Med. 2005;28(2):186-93.

65. Nicoll G. Spatial measures associated with stair use. Am J Health Promot. 2007;21(4_suppl):346-52. https://doi.org/10.4278/0890-1171-21.4s.346.

66. Bassett DR, Browning R, Conger SA, Wolff DL, Flynn Jl. Architectural design and physical activity: an observational study of staircase and elevator use in different buildings. J Phys Act Health. 2013;10(4):556-62.

67. McCormack GR, Shiell A. In search of causality: a systematic review of the relationship between the built environment and physical activity among adults. Int J Behav Nutr Phys Act. 2011;8(1):125.

68. Saelens BE, Sallis JF, Frank LD. Environmental correlates of walking and cycling: findings from the transportation, urban design, and planning literatures. Ann Behav Med. 2003:25(2):80-91.

69. Troped PJ, Saunders RP, Pate RR, Reininger B, Addy CL. Correlates of recreational and transportation physical activity among adults in a New England community. Prev Med. 2003;37(4):304-10

70. Vuori IM, Oja P, Paronen O. Physically active commuting to work--testing its potential for exercise promotion. Med Sci Sports Exerc. 1994;26(7):844-50.

71. Frank LD, Andresen MA, Schmid TL. Obesity relationships with community design, physical activity, and time spent in cars. Am J Prev Med. 2004;27(2): 87-96.

72. Wolff D, Fitzhugh EC. The relationships between weather-related factors and daily outdoor physical activity counts on an urban greenway. Int J Environ Res Public Health. 2011:8(2):579-89.

73. Suminski RR, Poston WC, Market P, Hyder M, Sara PA. Meteorological conditions are associated with physical activities performed in open-air settings. Int J Biometeorol. 2008;52(3):189-97.

74. Tucker $P$, Gilliland J. The effect of season and weather on physical activity: a systematic review. Public Health. 2007;121(12):909-22.

75. Flynn BS, Dana GS, Sears J, Aultman-Hall L. Weather factor impacts on commuting to work by bicycle. Prev Med. 2012;54(2):122-4.

76. Buehler R, Pucher J. Cycling to work in 90 large American cities: new evidence on the role of bike paths and lanes. Transportation. 2012;39(2): 409-32.

77. Nankervis M. The effect of weather and climate on bicycle commuting. Transp Res A Policy Pract. 1999:33(6):417-31

78. Cervero R, Duncan M. Walking, bicycling, and urban landscapes: evidence from the San Francisco Bay Area. (Author Abstract). Am J Public Health. 2003:93(9):1478

79. Rodríguez DA, Joo J. The relationship between non-motorized mode choice and the local physical environment. Transp Res Part D: Transp Environ. 2004; 9(2):151-73.

80. Heinen E, van Wee B, Maat K. Commuting by bicycle: an overview of the literature. Transp Rev. 2010;30(1):59-96.
81. Stinson M, Bhat C. Frequency of bicycle commuting: internet-based survey analysis. Transp Res Rec. 1878;1:122-30. https://doi.org/10.3141/1878-15.

82. Schwanen T, Dijst M. Travel-time ratios for visits to the workplace: the relationship between commuting time and work duration. Transp Res $A$ Policy Pract. 2002;36(7):573-92

83. Whitelaw S, Baxendale A, Bryce C, Machardy L, Young I, Witney E. 'Settings' based health promotion: a review. Health Promot Int. 2001;16(4):339-53.

84. Quyen G, Chen TL, Magnussen CG, Kien G. Workplace physical activity interventions: a systematic review. Am J Health Promot. 2013;27(6):e113-23.

85. Mullane SL, Toledo MJL, Rydell SA, Feltes LH, Vuong B, Crespo NC, Pereira MA, Buman MP. Social ecological correlates of workplace sedentary behavior. Int J Behav Nutr Phys Act. 2017;14(1):117.

86. Wright S, Hall Brown TS, Collier SR, Sandberg K. How consumer physical activity monitors could transform human physiology research. Am J Phys Regul Integr Comp Phys. 2017;312(3):R358-67.

87. Trost SG, Mclver KL, Pate RR. Conducting accelerometer-based activity assessments in field-based research. Med Sci Sports Exerc. 2005:37(11 Suppl):S531-43.

88. Intille S, Lester J, Sallis JF, Duncan G. New horizons in sensor development. Med Sci Sports Exerc. 2012;44(1 Suppl 1):S24-31.

89. Atkin AJ, Gorely T, Clemes SA, Yates T, Edwardson C, Brage S, Salmon J, Marshall SJ, Biddle SJ. Methods of measurement in epidemiology: sedentary behaviour. Int J Epidemiol. 2012;41(5):1460-71

90. Maddison R, Mhurchu CN. Global positioning system: a new opportunity in physical activity measurement. Int J Behav Nutr Phys Act. 2009;6(1):73.

91. Ogilvie D, Bull F, Powell J, Cooper AR, Brand C, Mutrie N, Preston J, Rutter H. An applied ecological framework for evaluating infrastructure to promote walking and cycling: the iConnect study. Am J Public Health. 2011;101(3): 473-81

92. McLeroy KR, Bibeau D, Steckler A, Glanz K. An ecological perspective on health promotion programs. Health Educ Q. 1988;15(4):351-77.

93. Jin $X$, Wah BW, Cheng $X$, Wang $Y$. Significance and challenges of big data research. Big Data Research. 2015:2(2):59-64

94. Strath SJ, Swartz AM, Bassett DR, O'Brien WL, King GA, Ainsworth BE. Evaluation of heart rate as a method for assessing moderate intensity physical activity. Med Sci Sports Exerc. 2000;32(9):S465-70.

95. Matthews CE, Hagstromer M, Pober DM, Bowles HR. Best practices for using physical activity monitors in population-based research. Med Sci Sports Exerc. 2012;44(1 Suppl 1):S68-76.

96. Murdoch TB, Detsky AS. The inevitable application of big data to health care. JAMA. 2013;309(13):1351-2.

97. Giles-Corti B, Donovan RJ. The relative influence of individual, social and physical environment determinants of physical activity. Soc Sci Med. 2002; 54(12):1793-812.

\section{Publisher's Note}

Springer Nature remains neutral with regard to jurisdictional claims in published maps and institutional affiliations.

\section{Ready to submit your research? Choose BMC and benefit from:}

- fast, convenient online submission

- thorough peer review by experienced researchers in your field

- rapid publication on acceptance

- support for research data, including large and complex data types

- gold Open Access which fosters wider collaboration and increased citations

- maximum visibility for your research: over $100 \mathrm{M}$ website views per year

At $\mathrm{BMC}$, research is always in progress.

Learn more biomedcentral.com/submissions 